\title{
CRIAÇÃO E COMPARTILHAMENTO DE CONHECIMENTO EM AMBIENTES VIRTUAIS DE ENSINO-APRENDIZAGEM
}

Mário Roberto Miranda Lacerda, Universidade Federal de Santa Catarina, mariolacerda8@gmail.com Maurício Rissi, Universidade Federal de Santa Catarina, mauriciorissi@cse.ufsc.br Marina Keiko Nakayama, Universidade Federal de Santa Catarina, marina@egc.ufsc.br Fernando José Spanhol, Universidade Federal de Santa Catarina, spanhol@led.ufsc.br Francisco Antonio Pereira Fialho, Universidade Federal de Santa Catarina, fapfialho@gmail.com Andressa Sasaki Vasques Pacheco, Universidade Federal de Santa Catarina, andressa.ufsc@gmail.com

\section{RESUMO}

Cada vez mais a sociedade necessita de fazer uso de tecnologias que, virtualmente, aproximam os saberes e as pessoas e também aproximam as pessoas entre si. Com isso, a necessidade de se elucidar o processo do conhecimento nessas "tecnologias virtuais" culmina com o objetivo deste estudo, que é o de verificar a criação e o compartilhamento de conhecimento em ambiente virtual de ensino-aprendizagem (AVEA). Este estudo caracterizase por ser bibliográfico, descritivo e qualitativo. Considera-se, por fim, que os conhecimentos autotranscendentes, tácitos e explícitos, dos diversos interagentes em AVEAs, acabam se tocando no imaginário, interligando-se no ciberespaço e construindo um basho nas nuvens de conhecimento.

Palavras-chave: criação e compartilhamento de conhecimento, ambientes virtuais, espaços de interação.

\begin{abstract}
Society must increasingly make use of technologies that virtually bring knowledge and people together, and bring people together with each other as well. Thus, the need to elucidate the process of knowledge in these "virtual technologies" culminates with the purpose of this study, which is to examine the production and sharing of knowledge in a virtual teaching and learning environment (AVEA). This study is characterized as being bibliographical, descriptive, and qualitative. It is understood, in conclusion, that the self-transcendent, tacit and explicit types of knowledge of the various interacting agents in the AVEAs end up by touching each other in the imaginary, connecting in cyberspace and building a Basho in the clouds of knowledge.
\end{abstract}

Keywords: production and sharing of knowledge; virtual environments; areas of interaction.

\section{Introdução}

Definir o que realmente é conhecimento é uma tarefa desafiadora, considerando que o conhecimento reside apenas na mente dos indivíduos e, ao mesmo tempo, pode ser capturado, armazenado e compartilhado (SPIEGLER, 2002). Isso faz com que o conceito de conhecimento não seja consensual, sendo que são várias as definições dadas pelos autores.

Para Sveiby (1998, p.43), o conhecimento pode ser entendido como "uma capacidade humana, de caráter tácito, orientada para a ação, baseada em regras, individual e em constante mutação". O autor afirma, ainda, que "seu conteúdo é revelado em ações de competência individual, isso porque, na prática, essa se expressa por meio de conhecimento explícito, habilidade, experiência, julgamento de valor e rede social”.

Por isso, criar novos conhecimentos, não significa, apenas, a capacidade de aprender com os outros ou de adquirir conhecimentos externos, mas também a capacidade de construir 
conhecimento por si mesmo, através da interação intensiva e laboriosa com muitos membros da organização, englobando ideais e ideias da organização e permitindo a tentativa e o erro (MORESI, 2001).

Os diferentes conceitos e ênfases existentes mostram que há a necessidade de se distinguir o que seja gestão do conhecimento, criação de conhecimento, gestão do capital intelectual, entre outros. Assim, a gestão do conhecimento não é uma simples questão de capturar, estocar e transferir informação, mas ela requer interpretação e organização da informação em múltiplas perspectivas (BHATT, 2001).

Assim, cada vez mais a sociedade precisa fazer uso de tecnologias que, virtualmente, aproximam os saberes e as pessoas e também aproximam as pessoas entre si. Com isso, a necessidade de se elucidar o processo do conhecimento, nessas "tecnologias virtuais", culmina com o objetivo deste estudo, que é o de verificar a criação e o compartilhamento de conhecimento em ambiente virtual de ensino-aprendizagem (AVEA).

\section{Procedimentos Metodológicos}

Esta pesquisa se caracteriza como sendo descritiva, bibliográfica e qualitativa. Ela é descritiva na medida em que expõe características de determinada população ou de um fenômeno (VERGARA, 1997). Mattar (1999) apresenta a pesquisa como sendo descritiva quando se procura o fenômeno em estudo.

A pesquisa bibliográfica, conforme Mattar (1999), caracteriza-se pela utilização de materiais publicados, como livros, revistas ou meios eletrônicos, através de sua identificação, seleção e análise. Para Martins (1994, p.28), "trata-se de estudo para conhecer as contribuições científicas sobre determinado assunto. Tem como objetivo recolher, selecionar, analisar e interpretar as contribuições teóricas já existentes sobre determinado assunto”.

Esta pesquisa tem, ainda, caráter qualitativo, pois os pesquisadores compreendem e interpretam os dados coletados na pesquisa a partir da percepção dos sujeitos de pesquisa e de documentos oficiais (CHIZZOTTI, 2001).

\section{A criação e o compartilhamento de conhecimento: a metáfora "espiral”}

Os pesquisadores Nonaka e Takeuchi (1997), em sua teoria da criação do conhecimento, apresentam uma construção teórica apoiada numa metáfora, a "espiral”, na qual os autores destacam as relações do conhecimento como sendo uma alternância entre suas expressões tácitas e explícitas, que emergem evolutivamente em processos de "socialização", “externalização”, “combinação” e "internalização”.

Grande parte da contribuição elucidativa dessa construção, referência para a área de Gestão do Conhecimento, talvez deva seu poder explicativo ao fato de pertencer ao imaginário humano, conforme exalta Morgan (2007):

Para se compreender de que maneira se constrói a teoria científica como uma forma simbólica, deve-se prestar atenção ao papel da metáfora, pois o processo de concepção metafórica é um modo básico de simbolismo, central para o modo como os humanos modelam sua experiência e seu conhecimento do mundo em que vivem. A metáfora é, com frequência, considerada não mais que um artifício literário e descritivo para efeitos decorativos; mas ela é, fundamentalmente, uma forma criativa que produz seu efeito pela intersecção ou sobreposição de imagens. (MORGAN, 2007, p.18)

A “espiral de criação do conhecimento", em sua simplicidade, revela-se como uma metáfora com alto poder de sobreposição, conduzindo a generalizações compreensivas de 
processos dinâmicos, onde o conhecimento, pelo seu compartilhamento, é convertido em novos conhecimentos.

Enquanto processo dinâmico de conversão, pelo intercâmbio de seus quatro modos, no primeiro movimento da espiral, o conhecimento tácito se converte em mais conhecimento tácito. Essa fase, denominada "socialização", representa o compartilhamento de experiências. De acordo com Nonaka e Konno (1998), “em certo sentido, o conhecimento tácito pode somente ser compartilhado se o indivíduo está livre para tornar-se um ser maior, que inclui o conhecimento tácito do outro", ou seja, é necessária uma abertura pessoal para a realidade "do outro". Num segundo momento, como “externalização”, é intensificada a explicitação do conhecimento, "expresso na forma de metáforas, analogias, conceitos, hipóteses ou modelos" (NONAKA; TAKEUCHI, 1997, p.71). A essência dessa etapa é a tradução do conhecimento tácito em formas compreensivas para o outro, ou seja, é torná-lo integrado ao mundo mental do grupo ao qual o indivíduo está inserido (NONAKA; KONNO, 1998).

Em seguida, há uma “combinação” do conhecimento recém-explicitado com o conhecimento explícito já existente, como uma sistematização de conceitos: "a reconfiguração das informações através da classificação, do acréscimo, da combinação e da categorização de conhecimento explícito” (NONAKA; TAKEUCHI, 1997, p.76). De acordo com Nonaka e Konno (1998), nesse estágio, as questões-chave podem ser encontradas nos processos de comunicação, difusão e sistematização do conhecimento. Por fim, o conhecimento explicitado pelo movimento da espiral é "internalizado"; o conhecimento explícito é incorporado como conhecimento tácito. Conforme destacam Nonaka e Takeuchi (1997), "é intimamente relacionado ao 'aprender fazendo"”. Essa etapa se estrutura na possibilidade de o indivíduo acessar o domínio do conhecimento do grupo, de forma que atualize conceitos, métodos, prática, estratégias, inovação, crescimento (NONAKA; KONNO, 1998).

O movimento da espiral é contínuo e envolve o universo simbólico das pessoas, seus pensamentos, visões de mundo, saberes, expertises, formas de expressão, anseios, receios, desejos e outros. O conhecimento, por sua vez, enquanto ativo intangível, pode ser representado como um todo fragmentado, complexo, que passa a fazer sentido quando interpretado à luz da significação dada a ele.

\section{Os espaços Ba de criação e compartilhamento de conhecimento: a metáfora "espacial”}

A partir desse reconhecimento, Nonaka e Konno (1998) buscaram ampliar a teoria de criação do conhecimento associando-a aos espaços $b a$, que apontam a plataforma chave dessa criação como um local "fenomenal". Tal local pode emergir em indivíduos, grupos de trabalho, times de projetos, círculos informais, reuniões temporárias, grupos de e-mail e no contato da linha de frente com os clientes. $B a$ oferece uma metáfora conceitual integrada para o modelo SECI (e.e., socialização, externalização, combinação e internalização), de conversão dinâmica de conhecimento.

Tendo como base esses pressupostos, pode-se interpretar que a metáfora da espiral se apoia e é permeada pela metáfora de $b a$, de forma que a espiral se movimenta dentro de um determinado "espaço". Essa correlação nos fornece elementos para melhor compreender e aplicar a teoria.

Segundo Nonaka e Konno (1998): "Cada ba apoia um processo de conversão particular e, por isso, cada ba acelera o processo de criação do conhecimento”. Estes se apresentam, em cada fase, nas seguintes definições:

Ba de início (ou origem), que está atrelado ao modo de conversão "socialização” (e.e., do conhecimento tácito para o tácito. Refere-se ao compartilhamento de sentimentos, emoções, experiências e modelos mentais entre os indivíduos. 
Ba de interação, que está atrelado ao modo de conversão "externalização” (e.e, do conhecimento tácito para o explícito). Refere-se ao diálogo, por meio do qual os modelos mentais e habilidades do indivíduo são convertidos em termos e conceitos comuns.

Cyber ba se vincula ao modo de conversão "combinação" (e.e, do conhecimento explícito para o explícito). Refere-se ao processo de onde os conhecimentos explícitos préexistentes são combinados com novas informações e conhecimentos. Nesse caso, há uma intensa utilização de meios virtuais: "O uso de redes on line, grupos de discussão, documentos e base de dados tem crescido na última década, destacando esse processo de conversão" (NONAKA; KONNO, 1998).

Exercitando ba (ou de exercício) se relaciona ao modo de conversão “internalização” (e.e, do conhecimento explícito para o tácito). Nesse processo, é destacado o uso do conhecimento formal (explícito) em atividades práticas, em situações reais ou simuladas.

O conceito de ba unifica os espaços físico, virtual e mental. Existindo em vários níveis, suas interconexões podem formar um ba maior, com propriedades emergentes, o que é denominado basho.

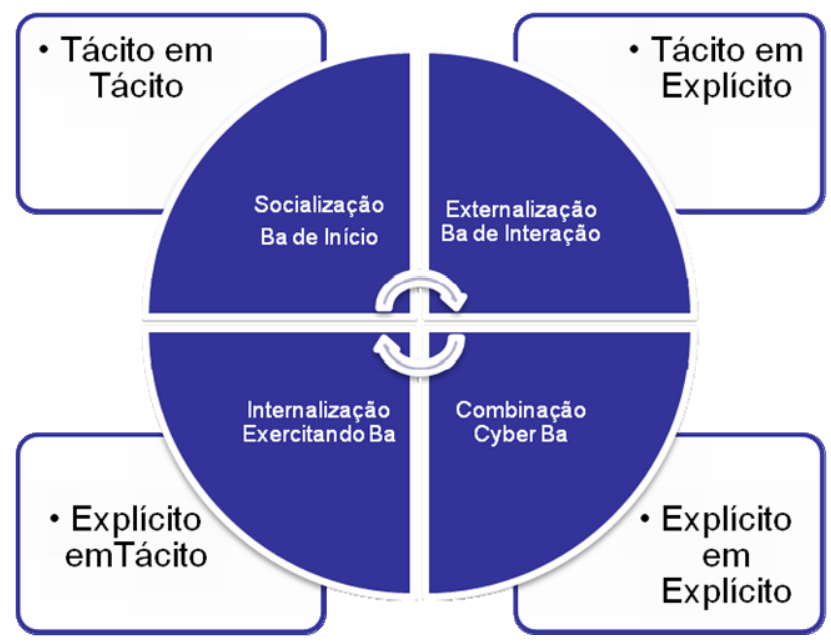

Figura 1: Quatro modos de conversão do conhecimento, relacionados aos tipos de ba. Fonte: Fialho (2009).

\section{O impulso da espiral de criação do conhecimento em $B a$}

Para que haja movimento da espiral de criação do conhecimento dentro de um espaço fenomenal $b a$, são necessárias condições favoráveis. Dentre elas, destaca-se certo impulso. Nonaka e Konno (1998) tecem reflexões nesse sentido: "Dentro de ba, a criação do conhecimento em tempo real é alcançada por meio da autotranscendência”. Porém, tal conceito não é amplamente desenvolvido pelos autores.

Shamer (2000) resgata esse insight inicial, relacionando-o com uma categoria de conhecimento anterior ao tácito, o "conhecimento autotranscendente", ou, "ainda não incorporado". Na busca por evidenciar a força que impulsiona a espiral do conhecimento, o autor apresenta uma categoria de conhecimento incipiente, onde a realidade é trazida à existência por um ato de “intuição-ação” (Nishida) ou de "presenciar” (Husserl, Heidegger).

Tais ideias têm origem na construção teórica de Kitaro Nishida, filósofo japonês da escola de Kyoto, contemporâneo de Freud e Husserl, e cuja filosofia tem como essência a “experiência pura”. Segundo Bin (1991, p.74), esta é: 
verbalização real ou potencial; é de uma importância fundamental como lugar autêntico de encontro vivo entre o homem e o mundo; enquanto os esforços do eu articulando e diferenciando conceitualmente as experiências serão considerados uma construção secundária derivada.

Implícita no conceito de "conhecimento autotranscendente" (SHAMER, 2000), um hiato ao ba de início (NONAKA; KONNO, 1998), a "experiência pura" aparece "como lugar em que uma certa realidade originária é experimentada sob um modo imediato, antes de qualquer construção verbal de realidades particulares e antes de qualquer consciência de si de um eu individual, sem mediação como tal” (BIN, 1991).

O conhecimento autotranscendente, ainda não incorporado, pode ser relacionado ao imaginário (Durand), inconsciente coletivo (Jung), ou, ainda, vinculado aos níveis de consciência e desenvolvimento dos indivíduos (LOEVINGER, 1976; 1979; 1998; WILBER, 1997; 2007), que "significam suas experiências" de maneira mais abrangente, na medida em que os níveis são ascendidos.

\section{A criação e o compartilhamento de conhecimentos em ambientes virtuais de ensino e aprendizagem}

As metáforas sobrepostas da espiral de criação do conhecimento - seus espaços $b a$, impulsionados por uma força autotranscendente - e a forma como os indivíduos significam suas experiências, podem ser aplicadas aos estudos da área de mídia do conhecimento. Nestes, os ambientes virtuais de ensino-aprendizagem são representados como $b a$, e os tipos de interação que emergem nesse ambiente propiciam a alternância entre conhecimento tácito e explícito, entre alunos, tutores e professores. De acordo com Almeida (2003, p.239):

[...] os ambientes virtuais de aprendizagem são: [...] sistemas computacionais
disponíveis na internet, destinados ao suporte de atividades mediadas pelas
tecnologias de informação e da comunicação. Permitem integrar várias mídias,
linguagens e recursos, apresentar informações de maneira organizada,
desenvolver interações entre pessoas e objetos do conhecimento, elaborar e
socializar produçôes, tendo em vista atingir determinados objetivos.

Os avanço das tecnologias de informação e comunicação, além da qualificação dos ambientes virtuais de ensino-aprendizagem, propiciam um espaço ba onde diversos tipos de interações entre pessoas e objetos do conhecimento se destacam. Mattar (2009) apresenta os seguintes:

a) Aluno/professor: podendo ser síncrona ou assíncrona, esse tipo de interação objetiva tanto a motivação dos alunos como o feedback dado a eles, sendo fundamental a sua ocorrência dentro de um timing que favoreça a aprendizagem.

b) Aluno/conteúdo: o conteúdo pode ser constituído de som, texto, imagens, vídeos, realidade virtual, com os quais o aluno interage navegando, explorando, selecionando, controlando, construindo, respondendo.

c) Aluno/aluno: caracteriza o denominado aprendizado colaborativo e cooperativo. Essa interação cria um senso de pertencimento e gera motivação e atenção.

d) Professor/professor: são as oportunidades de interação entre professores, na troca de insights pedagógicos, na criação de comunidades virtuais.

e) Professor/conteúdo: os professores interagem com o conteúdo comentando-o, sugerindo fontes de consulta, propondo atividades, mudando o currículo.

f) Conteúdo/conteúdo: um tipo complexo de interação, onde programas semiautônomos, pró-ativos, adaptativos ajustam o conteúdo. 
g) Aluno/interface: um curso de EAD pode funcionar simultaneamente como um curso de inclusão digital. Segundo Lévy (1993, p.11 apud MATTAR, 2009, p.117): “A técnica e as tecnologias intelectuais, em particular, têm muitas coisas para ensinar aos filósofos sobre a filosofia, e aos historiadores, sobre a história”.

h) Autointeração: durante o processo de aprendizagem, o aluno "conversa consigo mesmo", reflete sobre o conteúdo, os tipos de interação, adota outras perspectivas.

i) Interação vicária: uma interação silenciosa, em que o aluno observa as discussões e debates sem deles participar ativamente.

j) Aluno/ambiente: de acordo com Burnham e Wladen (1997 apud MATTAR, 2009, p.117): é "uma ação recíproca ou influência mútua entre o aluno e seu entorno que ajuda ou prejudica o aprendizado".

k) Aluno/outro: conforme Hirumi (2002 apud MATTAR, 2009), essa interação envolveria as fontes totalmente externas ao ambiente de ensino-aprendizagem.

Os espaços de criação e compartilhamento de conhecimento emergem das interações a partir do impulso autotranscendente adotado pelo aluno. Esse impulso talvez possa, em parte, ser caracterizado pela autonomia na jornada de autoaprendizagem. Nesta, a interação vicária e a autointeração provavelmente sejam conceitos essenciais para melhor compreender a fase de socialização (ba de início), uma vez que as peculiaridades dos AVEAs levam os alunos a compartilharem sentimentos, emoções, experiências e modelos mentais de uma forma mais silenciosa e introspectiva, porém propiciando uma realidade compartilhada, fazendo com que se identifiquem “ao outro” e, tacitamente, aprendam em grupo.

O ambiente virtual de aprendizagem é o local especialmente disponibilizado para depositar o material referente às disciplinas, bem como para realizar a sua troca. Ele só é possível graças à rede mundial de computadores, em que pessoas de diferentes lugares participam do mesmo ambiente colaborativo.

A importância do ambiente colaborativo está em proporcionar o contato com diversos usuários e de ser um "local” onde estes disponibilizam e trocam informações, que podem ser artigos, indicações de sites, imagens, textos em geral, vídeos, entre outros. A possibilidade de uma pessoa enriquecer o seu conhecimento a partir do contato com outras é muito significante. A troca de experiências que se dá na reunião de pessoas, tenham elas interesses iguais ou não, tende a acrescentar conhecimento a cada uma delas (URIARTE, 2003).

O ambiente colaborativo pode ser: uma sala para chat, onde os usuários conversam e trocam informações; um fórum virtual, onde acontecem discussões on line; um mural, onde são colocadas notícias ou informes; uma biblioteca virtual, onde o professor expõe exercícios para os alunos resolverem, e textos complementares ao material didático; uma ferramenta que disponibiliza o contato com o tutor; e qualquer outro ambiente existente na internet com a finalidade de proporcionar a troca de informações, a colaboração entre os usuários (DALMAU et al, 2007).

No ambiente virtual de aprendizagem, a comunicação pode se dar de maneira síncrona ou assíncrona. Diz-se que a comunicação é síncrona quando os usuários estão conectados ao mesmo tempo, no mesmo canal de comunicação, permitindo a comunicação instantânea, como no caso do chat, a videoconferência e o telefone. A comunicação é assíncrona quando não se faz necessária essa sincronia de tempo, como no caso do e-mail, fórum, vídeo-aula, mural, biblioteca, entre outros. Dalmau et al (2007) complementam a descrição das ferramentas utilizadas para gerir o conhecimento nos ambientes virtuais de aprendizagem como segue abaixo.

O “fórum" é uma ferramenta que permite a discussão, pelos integrantes, sobre um tema proposto de forma assíncrona. Através dele, os estudantes, têm a oportunidade de trocar ideias e experiências com outros estudantes, com os professores e com os tutores. 
O “tutor” é o responsável por conduzir o debate, para que este não perca o seu foco principal e também para instigar os alunos à participação. Faz-se necessária uma metodologia para conduzir esse tipo de atividade, na qual os assuntos abordados devem ser relevantes e estimulantes à discussão por parte dos alunos (DALMAU et al., 2007).

A vantagem do fórum é que o número de participantes pode ser grande, gerando assim debates com opiniões as mais variadas possíveis. Outra vantagem é que as mensagens postadas ficam registradas, para que qualquer usuário tenha acesso a elas em qualquer tempo, podendo ser respondidas por quem o visita e, com isso, o professor pode ter um histórico do debate e fazer o acompanhamento dos alunos com maior facilidade (DALMAU et al., 2007).

A conveniência do fórum é que, como tudo fica disponível todo o tempo, não é necessário que as pessoas que o frequentam estejam on line no momento em que uma questão é enviada, e nem que a pessoa que a postou esteja on line no momento em que sua questão foi respondida. Os problemas que podem ser encontrados dizem respeito à fuga do tema e à baixa interação, sendo essencial a participação do tutor para evitá-los (DALMAU et al., 2007).

No caso específico do fórum, pode ser claramente vislumbrada a interação vicária citada anteriormente, através da qual, mesmo não participando ativamente, o aluno acompanha as discussões e com isso aprende, reflete e cria conhecimento.

O “chat” é uma ferramenta de comunicação síncrona, em modo texto, podendo ser coletiva ou individualizada, permitindo que as discussões se deem de forma mais interativa.

Para Dalmau et al (2007), a comunicação é coletiva quando os usuários enviam mensagens para todos os usuários conectados ao canal e as recebem igualmente de todos. Na comunicação individual, é possível ao usuário escolher um integrante específico do canal, para comunicar-se direta e exclusivamente com ele. Também é possível comunicar-se individualmente com mais de um usuário de forma simultânea, mantendo conversas paralelas.

Outra vantagem do chat, de acordo com Dalmau et al. (2007), é a possibilidade de marcar reuniões com professores, tutores e estudantes em horários pré-determinados e poder discutir com eles os assuntos em tempo real, aproximando-se da forma como os debates são realizados em sala de aula. Tal funcionalidade não é fornecida pelo fórum. Para se conduzir uma atividade com o chat, é necessária uma metodologia para que se alcancem os objetivos, e as turmas devem ser pequenas.

A ferramenta chat possibilita diversas interações, aproximando pessoas de pessoas, sejam alunos-tutor, aluno-professor, aluno-aluno, e com diversas outras possibilidades, onde virtualmente ocorrem todos os processos $b a$.

Uma desvantagem do chat é a de que todos os usuários devem estar conectados ao mesmo tempo, rompendo com a flexibilidade de horários. Há ferramentas de “log de chat”, que permitem a gravação das conversas, e o aluno pode consultar posteriormente o que foi discutido, além de o professor poder acompanhar os debates (DALMAU et al, 2007).

A “videoconferência” é uma tecnologia que permite fazer, de forma virtual, reuniões, treinamentos, aulas, defesa de Tese, conferências ou debates, com som e imagem em tempo real, e com interatividade entre os participantes, via internet ou outro link de comunicação de alto desempenho.

$\mathrm{Na}$ videoconferência, os participantes estão em locais diferentes, mas podem ver e ouvir uns aos outros como se estivessem num mesmo local. Esses sistemas permitem que se trabalhe de forma cooperativa, compartilhando informações e materiais de trabalho sem a necessidade de locomoção geográfica. A maioria das videoconferências atualmente envolve o uso, em cada localidade geográfica, de uma sala dotada de uma videocâmera especial e facilidades para a apresentação de documentos. A videoconferência tradicional geralmente requer interconexão especial através do telefone ou da internet com grande largura de banda (DALMAU et al., 2007). 
O "FAQ” (Frequently Asked Questions), que significa “perguntas frequentes”, é uma ferramenta on line muito utilizada na educação à distância. Ela é adotada numa tentativa de reduzir o número de perguntas semelhantes colocadas pelos alunos (DALMAU et al, 2007). Essa ferramenta tem como vantagem a disponibilização dessas informações aos estudantes por tempo indeterminado. As perguntas e respostas devem estar organizadas de uma forma lógica e apresentar objetividade e clareza.

Os "exercícios de aprendizagem” servem como atividades individuais ou coletivas, que têm como objetivo principal acompanhar o desenvolvimento do aluno acerca dos conteúdos abordados nas disciplinas e mensurar o seu aprendizado. Geralmente são disponibilizados no ambiente virtual de aprendizagem, com tempo pré-determinado para sua realização (DALMAU et al, 2007).

$\mathrm{Na}$ medida em que o aluno segue sua jornada de aprendizagem, as interações aluno/professor, estabelecidas no diálogo - principalmente por meio de feedbacks (dentro de um time) - tornam-se fator chave na fase de externalização (ba de interação).

Ao aprofundar o estudo das disciplinas, a interação entre aluno/conteúdo, complementada pela interação aluno/aluno, pode ampliar consideravelmente as possibilidades de combinação, ou mesmo de releitura do conhecimento, favorecendo a contextualização e a leitura interdisciplinar dos conteúdos apresentados. As interações professor/professor, professor/conteúdo, conteúdo/conteúdo, aluno/interface representam elementos importantes para a superação das restrições da mediação tecnológica (permeada por interfaces) e a estruturação de ambientes virtuais de ensino-aprendizagem voltados à criação e ao compartilhamento de conhecimento.

Da mesma forma, fóruns de discussão bem aproveitados (mediados, evoluindo e aprofundando as problematizações), atividades colaborativas, avaliações à distância, pesquisas e outros recursos pedagógicos podem ser ferramentas importantes na fase de combinação (Cyber ba).

Para Caixeta et al. (2007), o ambiente virtual de aprendizagem exerce um papel fundamental na educação à distância. Essa ferramenta permite a comunicação e a interatividade entre os agentes envolvidos no processo de ensino. Além disso, as informações são disponibilizadas de tal forma que o estudante pode ter acesso a todo material didático do curso e às informações acerca de seu desempenho e da programação de atividades da disciplina.

Para a de criação de ambientes virtuais de aprendizagem, em que pessoas possam gerar aprendizagem, existe a necessidade de readequação e utilização de ferramentas de colaboração ou mesmo de criação de novos ambientes que privilegiem a comunicação, autonomia, criatividade e compartilhamento de conhecimento entre os atores do processo de aprendizagem (MARTINS, 2002 apud CAIXETA et al., 2007).

O processo de desenvolvimento de um ambiente de EAD é mais amplo do que o ato de traduzir aulas presenciais para um ambiente web. O desenvolvimento de um ambiente para suporte ao processo de aprendizagem que utiliza as tecnologias de informação e comunicação pressupõe um cuidadoso planejamento. A topologia desse ambiente é dada por uma rede de articulações de estratégias e táticas pedagógicas, as quais são definidas a partir dos objetivos e pressupostos pedagógicos (ANDRADE; BEILER; WAGNER, 2001 apud CAIXETA et al, 2007).

Atualmente, vários autores da área de educação à distância destacam a importância de uma comunicação motivadora e diferenciada, nesse tipo de modalidade, que objetive melhorias no processo de ensino e aprendizagem virtuais (CAIXETA et al., 2007).

Por fim, as interações aluno/ambiente e aluno/outro, onde o conhecimento passa a ser utilizado numa prática, e a ação individual acaba sendo modificada a partir do 
conhecimento adquirido, talvez possa nos fornecer elementos para caracterizar a fase de internalização (exercitando $b a$ ) em AVEAs.

\section{Considerações finais}

Nas palavras de Fialho e Coelho (2007), "todos os mundos são mundos virtuais e todos os espaços são ciberespaços”. Tal afirmação nos convida a interpretar os ambientes virtuais de ensino-aprendizagem como tendo as mesmas possibilidades para a criação e o compartilhamento de conhecimento que os ambientes "presenciais". A reflexão sobre os modelos mentais como representações da realidade evidenciam que as interações virtuais, com seus graus de "intimidade" ou "profundidade", são tão reais quanto as interações realizadas de forma mais tradicional (e.e., face a face).

A sobreposição de metáforas nos desafia a imaginar uma espiral de criação do conhecimento se movimentando em espaços $b a$, sob a influência propulsora de uma força autotranscendente, presente na própria consciência humana. Trata-se de um convite às novas interpretações, que ressoem e construam as palavras de Nonaka e Konno (1998), segundo as quais ba existe em vários níveis e esses níveis podem ser conectados para formar um ba maior (basho).

Nos ambientes virtuais de ensino-aprendizagem, os tipos de interação pressupõem a construção de uma realidade compartilhada entre indivíduos com diferentes tipos de conhecimento tácito e explícito (NONAKA; TAKEUCHI, 1997). A partir dessas interações em $b a$, criam-se contextos que fomentam significados, onde os níveis de $b a$ podem ser relacionados aos níveis de consciência e desenvolvimento dos indivíduos (LOEVINGER, 1976; 1979; 1998; WILBER, 1997, 2007), que dão significado mais abrangente às suas experiências na medida em que os níveis são ascendidos.

Os conhecimentos autotranscendentes, tácitos e explícitos, dos diversos interagentes em AVEAs, acabam se tocando no imaginário, interligando-se no ciberespaço e construindo um basho nas nuvens de conhecimento. O desafio da área de Mídia do Conhecimento é tornar esta realidade inteligível a um maior número de pessoas, ampliando ainda mais a espiral de criação do conhecimento.

\section{REFERÊNCIAS}

ALMEIDA, M. E. Educação, ambientes virtuais e interatividade. In: Silva, M. Educação on-line. São Paulo: Loyola, 2003.

BHATT, G. D. Management strategies for individual knowledge and organizational knowledge. Journal of Knowledge Management. v. 6, n. 1, 2002, p. 31-39.

BIN, Kimura. Significação e limite da linguagem na formação psicoterapêutica. Rev. Latinoam. Psicopat. Fund., VI, 3, 70-82. Tradução de François Bideaux e Joël Bouderlique, a partir do texto alemão intitulado "Bedeutung der Sprache in der psychotherapeutischen Ausbildung. Tradução para o português de Monica Seincman. Publicado originalmente em Pierre Fédida et Jacques Schotte (org.). Psychiatrie et existence. Grenoble: Editions Jérôme Millon, 1991, p.199-212.

CAIXETA, D. R. A. et al. O Ambiente Virtual de Aprendizagem (AVA) no Curso de Graduação em Administração na Modalidade à Distância da Universidade Federal de Santa Catarina. In: VII Colóquio Internacional sobre Gestão Universitária na América do Sul.

Anais... Mar Del Plata, 2007.

CHIZZOTTI, A. Pesquisa em Ciências Humanas e Sociais. 5a ed. São Paulo: Cortez, 2001. 
DALMAU, M. B. L. et al. O processo de gestão do conhecimento em uma instituição de ensino superior: um estudo de caso considerando a oferta de um curso de graduação à distância. In: $4^{\circ}$ Congresso Internacional de Gestão da Tecnologia e Sistemas de Informação, 2007, São Paulo. Anais... CONTECSI, 2007.

FIALHO, F. A. P.; COELHO, C.C. S. R. Espaços Digitais para Melhor Aprendizagem. In: Revista Diálogo Educacional: Programa de Pós-Graduação Stricto Sensu em Educação PUCPR, Curitiba, v. 7, n. 22, p.165-174, set/dez. 2007. Quadrimestral.

LOEVINGER, J. (Ed.). Technical foundations for measuring ego development: the Washington University Sentence Completion Test. New Jersey: Lawrence Erlbaum, 1998.

Construct validity of the ego development test. Applied Psychological Measurement, v. 3, p. 281-311, 1979. 1976.

Ego development: conception and theories. San Francisco: Jossey-Bass Publishers,

MATTAR, F. N. Pesquisa de Marketing. 5ªed. v.1. São Paulo: Atlas, 1999.

MATTAR, J. Interatividade e aprendizagem. In: LITTO, F. M.; FORMIGA, M. Educação à Distância: o estado da arte. São Paulo: Pearson Education do Brasil, p.112-120, 2009.

MORESI, E. A. D. Gestão da Informação e do Conhecimento. IN: TARAPANOFF, K. O. Inteligência Organizacional e Competitiva. Brasília: Editora Universidade de Brasília, 2001, p. 111-142.

MORGAN, G. Paradigmas, metáforas e resolução de quebra-cabeças na teoria das organizações. In: CALDAS, M. P.; BERTERO, C. Teoria das Organizações. São Paulo: Atlas, 2007, p.12-33.

NONAKA, I.; KONNO, N. The Concept of "Ba": Building a Foundation for Knowledge Creation. In: California Management Review. v. 40, n. 3, p. 40-54, 1998.

NONAKA, I.; TAKEUCHI, H. A Criação de Conhecimento na Empresa. Rio de Janeiro: Campus, 1997.

SCHARMER, C. O. Self-Transcending Knowledge: Sensing and Organizing Around Emerging Opportunities, forthcoming. In: Nonaka, I.; D. Teece (ed.): Managing Industrial Knowledge. Sage (in press) Japanese translation in: Soshiki Kagaku (Organizational Science), Vol. 33, No. 3, 2000, p. 14-29,

SPIEGLER , I. Technology and knowledge: bridging a "generating”' gap. Disponível em: <http://www.sciencedirect.com>. 2002. Acesso em: 25 nov. 2004.

SVEIBY, K. E. A nova riqueza das organizações: gerenciando e avaliando patrimônios do conhecimento. Rio de Janeiro: Campus, 1998.

URIARTE, L. R. Modelo de Ambiente para Orientação à Distância. 185 f. Tese (Doutorado em Engenharia da Produção). Universidade Federal de Santa Catarina, Florianópolis, 2003.

WILBER, K. An Integral Theory of Consciousness. Journal of Consciousness Studies, v. 4, n.1, p. 71-92, 1997.

Psicologia Integral: Consciência, Espírito, Psicologia, Terapia. $2^{\mathrm{a}}$ ed. São Paulo: Cultrix, 2007.

VERGARA, S. M. Projetos e Relatórios de Pesquisa em Administração. São Paulo: Atlas, 1997. 